\title{
ATENDIMENTO A ESTUDANTES DE ALTAS HABILIDADES/ SUPERDOTACÃO NA REDE ESTADUAL DE ENSINO DE CAMPO GRANDE DE 2005 A 2018
}

\author{
SERVICE TO HIGH SKILLS / STUDENT STUDENTS AT THE CAMPO GRANDE \\ STATE EDUCATION NETWORK FROM 2005 TO 2018
SERVICIO A ALTAS HABILIDADES / ESTUDIANTES ESTUDIANTES EN LA RED DE EDUCACIÓN ESTATAL DE CAMPO GRANDE DE 2005 A 2018

Priscilla Basmage Lemos Drulis*

(iD) https://orcid.org/oooo-0003-0622-2504

Antonio Sales**

http://orcid.org/oooo-ooo1-5515-6625

\begin{abstract}
REVISTA PEDAGÓGICA
Revista do Programa de Pós-graduação em Educação da Unochapecó | ISSN 1984-1566 Universidade Comunitária da Região de Chapecó | Chapecó-SC, Brasil Como referenciar este artigo: DRULIS, P. B.; SALES A. Atendimento a estudantes de altas habilidades/superdotação na rede estadual de ensino de Campo Grande de 2005 a 2018. Revista Pedagógica, Chapecó, v. 22, p. 1-19, 2020. DOI: https://doi.org/10.22196/rp.v22io.5673
\end{abstract}

Resumo: O presente texto expõe o resultado da pesquisa de cunho bibliográfico trabalhado na disciplina de Educação Especial e Processo de Escolarização, do Programa de Mestrado Profissional e Educação da Universidade Estadual de Mato Grosso do Sul, que partiu de uma inquietação pessoal de como se constituiu a história sobre Altas Habilidades/Superdotação (AH/ SD) até a atualidade com a criação do Centro Estadual de Atendimento Multidisciplinar para Altas Habilidades/ Superdotação (CEAM/AHS). Assim o objetivo deste estudo é realizar um breve histórico do atendimento às pessoas com $\mathrm{AH} / \mathrm{SD}$ em âmbito nacional e local até a criaçao do CEAM/AHS na rede estadual de ensino de Campo Grande - MS, assim como o trabalho realizado pelo referido Centro. Como procedimento metodológico foi realizado o levantamento, a seleção e o estudo de livros, legislação e artigos. Os resultados obtidos com a pesquisa revelam que a temática Altas Habilidades/Superdotação ainda está em crescimento no cenário educacional. Mesmo que se fala há muito tempo sobre isso, a prática ainda está aquém, caminhando para o esperado reconhecimentos destes indivíduos superdotados e um trabalho adequado visando a inclusão.

Palavras-chave: Educação Especial. Atendimento ao Superdotado. CEAM/AHS.

Abstract: This text exposes the result of bibliographic research worked in the discipline of Special Education and Schooling Process, of the Professional Master's Program and Education of the State University of Mato Grosso do Sul, which started from a personal concern about how it was constituted the story about High Skills / Giftedness (AH / SD) until today with the creation of the State Center for Multidisciplinary Service for High Skills / Giftedness (CEAM / AHS). Thus, the objective of this study is to carry out a brief history of care for people with AH / SD at national and local levels until the creation of CEAM / AHS in the state school system of Campo Grande - MS, as well as the work carried out by the referred Center. As a methodological procedure, the survey, selection and study of books, legislation and articles were carried out. The results obtained with the research reveal that the theme High Skills / Giftedness is still growing in the educational scenario, even if it has been talked about for a long time, the practice is still falling short, moving towards the expected recognition of these gifted individuals and an adequate job towards inclusion.

Keywords: Special Education. Attendance to the Gifted. CEAM / AHS.

Resumen: Este texto expone el resultado de la investigación bibliográfica trabajada en la disciplina de Educación Especial y Proceso de Educación, del Programa de Maestría Profesional y Educación de la Universidad Estatal de Mato Grosso do Sul, que comenzó con una preocupación personal sobre cómo se constituyó. La historia sobre las Altas Habilidades / Dotación (AH / SD) hasta hoy con la creación del Centro Estatal de Servicio Multidisciplinario para las Altas Habilidades / Dotación (CEAM / AHS). Por lo tanto, el objetivo de este estudio es llevar a cabo una breve historia de atención para personas con AH / SD a nivel nacional y local hasta la creación de CEAM / AHS en el sistema escolar estatal de Campo Grande - MS, así como el trabajo realizado por el referido Centro. Como procedimiento metodológico, se 
realizó la encuesta, selección y estudio de libros, legislación y artículos. Los resultados obtenidos con la investigación revelan que el tema High Skills / Giftedness todavía está creciendo en el escenario educativo, incluso si se ha hablado durante mucho tiempo, la práctica todavía se está quedando corta, avanzando hacia el reconocimiento esperado de estos individuos dotados y un trabajo adecuado hacia la inclusión.

Palabras clave: Educación Especial. Asistencia a los dotados. CEAM / AHS.

\section{Introdução}

Quando se discute sobre a Educação Especial é comum, num primeiro momento, lembrar do aluno que compõe o público dessa modalidade de ensino como aquele com deficiência intelectual, auditiva, visual, física, isto é, pensar a deficiência.

Porém, sabemos que além das diversas deficiências, temos também as diversas habilidades que podem ser identificadas como altas habilidades/superdotação. São comportamentos observados e/ou relatados que confirmam a expressão de que existem "traços consistentemente superiores" em relação a uma média. Como parâmetro citam-se a idade, produção ou série escolar em qualquer campo do saber ou do fazer. (BRASIL, 1995, p. 13).

Deve-se entender por "traços" as formas consistentes, ou seja, aquelas que permanecem com frequência e duração no repertório comportamental da pessoa, de forma a poderem ser registradas em épocas diferentes e situações semelhantes (BRASIL, 1995, p. 13).

Em Rebelo (2012, p. 11) encontra-se a informação de que a

Política Nacional de Educação Especial na Perspectiva da Educação Inclusiva instituída em 2008 trouxe em seu texto que o Estado brasileiro, entre demais ações deveria garantir a transversalidade da educação especial em todo o percurso escolar do aluno com deficiência, transtornos globais de desenvolvimento e altas habilidades/superdotação reafirmando o direito ao atendimento educacional especializado.

Tal política teria a função de apoiar a educação escolar no ensino regular. A partir de então a educação especial não deveria mais ser substitutiva à escolarização comum, algo que, segundo o texto citado, persistia até aquele momento uma vez que o atendimento dessas pessoas estava relegado, em grande parte dos casos, às instituições privado-assistenciais com subvenção do Estado. Em seu prólogo, a Política de 2008 se apresenta na posição de alterar esse quadro afirmando a busca por "superar a oposição entre educação regular e educação especial” (BRASIL,

\begin{abstract}
* Mestranda em Educação na Universidade Estadual de Mato Grosso do Sul (UEMS). Possui graduação em Pedagogia pela Universidade Católica Dom Bosco (2004). Atua como professora do Atendimento Educacional Especializado do Centro Estadual de Atendimento Multidisciplinar para altas habilidades/ superdotação (CEAM/AHS).

E-mail: pribasmage@hotmail.com
\end{abstract}

\footnotetext{
** Doutorado em Educação pela Universidade Federal de Mato Grosso do Sul. Atualmente é Docente Sênior da Universidade Estadual de Mato Grosso do Sul e Docente da Universidade AnhangueraUniderp.

E-mail: profesales@hotmail.com
} 
2008, p. 5). O documento ainda afirmava que a educação brasileira até aquele momento não tinha se organizado na perspectiva da inclusão.

Segundo dados do Relatório de Gestão Consolidado do MEC, Exercício 2015, no período de 2005 a 2014, foram implantadas 17.500 salas de recursos multifuncionais em 4.785 municípios e atualizadas 30 mil salas existentes (BRASIL, 2016, p.43).

Assim como essas crianças ou jovens com deficiências, também os alunos com altas habilidades necessitam e têm direito ao atendimento especializado, pois integram o público alvo da Educação Especial (RECH; FREITAS, 2004).

Renzulli (1986, p. 76) defende a ideia de que deve haver uma mudança no enfoque das definições de superdotação de "ser ou não ser superdotado" para "desenvolver comportamentos superdotados". Assim, a visão de superdotação como um fenômeno inato e cristalizado seria substituída por uma visão mais dinâmica e flexível, levando-se em consideração à importância da interação entre indivíduo e ambiente no desenvolvimento de comportamentos superdotados e não apenas o conceito de Quociente de Inteligência.

A problemática que resultou na pesquisa partiu de uma inquietação pessoal de como se constituiu o histórico sobre Altas Habilidades/Superdotação até a atualidade com a criação do CEAM/AHS (Centro Estadual de Atendimento Multidisciplinar para Altas Habilidades/Superdotação), já que na literatura apresentada existem poucas informações acerca do tema.

Esse estudo é de caráter bibliográfico. A pesquisa realizada é de cunho bibliográfico tendo como suporte os textos trabalhados na disciplina Educação Especial e Processos de Escolarização e embasados em outras fontes como livros, artigos, e documentos da área abordada.

O tema deste artigo surgiu por meio da experiência vivida por oito anos como técnica do Centro Estadual de Atendimento Multidisciplinar para Altas Habilidades/Superdotação (CEAM/AHS), anteriormente chamado Núcleo de Atividades de Altas Habilidades/Superdotação (NAAH/S).

O objetivo deste estudo é realizar um breve histórico do atendimento às pessoas com Altas Habilidades/ Superdotação em âmbito nacional e local até a criação do CEAM/AHS na rede estadual de ensino de Campo Grande - MS. Inclui também, o trabalho realizado pelo referido Centro, com o intuito de colaborar com a pesquisa, aprimoramento profissional e técnico na área. Pretende-se ainda contribuir com a promoção do atendimento qualificado a essas pessoas, promovendo conhecimento acerca do tema. Por isso, justifica-se a realização desta pesquisa, com o 
intuito de aprofundar os estudos para uma compreensão mais fundamentada e estruturada sobre aspectos subjetivos que cercam as pessoas com altas habilidades/superdotação e o atendimento dispensado a elas pelo CEAM.

\section{Metodologia}

Esse artigo é uma pesquisa de cunho bibliográfico, sobre o histórico das altas habilidades/superdotação no Brasil até a criação do CEAM/AHS, assim como o trabalho desempenhado na rede estadual de ensino de Campo Grande.

A pesquisa bibliográfica foi realizada através de estudos e pesquisas em diversas fontes como: Livros, Revistas, Artigos, Sites da Internet e entre outros, buscando unir maior número de subsídios e fundamentação teórica para embasar essa pesquisa.

[...] a pesquisa bibliográfica trata-se do levantamento, seleção e documentação de toda bibliografia já publicada sobre o assunto que está sendo pesquisado, em livros, revistas, jornais, boletins, monografias, teses, dissertações, material cartográfico, com o objetivo de colocar o pesquisador em contato direto com todo material já escrito sobre o mesmo (LAKATOS; MARCONI, 1987, p. 66).

Neste artigo, nos atentaremos ao Núcleo de Atividades de Altas Habilidades/Superdotação NAAH/S - MS, que desde 2017 foi transformado em Centro Estadual de Atendimento Multidisciplinar para Altas Habilidades/ Superdotação CEAM/AHS - MS, instituído em parceria com a Secretaria de Educação do Estado de Mato Grosso do Sul (SED/MS), que dirige suas ações aos alunos matriculados na Rede Estadual de Ensino com indicativo de altas habilidades/superdotação. O CEAM/AHS - MS está subordinado à Coordenadoria de Educação Especial da Superintendência de Políticas de Educação da SED/MS.

Para melhor compreensão sobre o que é, como atua e quais as atribuições e ações do NAAH/S - MS, não se pode deixar de mencionar a legislação que rege o Núcleo, bem como compreender que o mesmo está vinculado e diretamente ligado à educação especial. Assim, fazse necessário ainda, apresentar a legislação que define, identifica e trabalha com alunos com altas habilidades/ superdotação, bem como o surgimento do Centro.

\section{Um pouco sobre a história das altas habilidades/superdotação no Brasil}

No Brasil há influência de muitos acontecimentos mundiais e históricos, em meios a muitos mitos sobre os 
superdotados. Segundo Cupertino (2012), assim como nos Estados Unidos, sofremos o impasse de transigir a igualdade e a excelência no ensino, e isso marcou e marca até os dias de hoje nossas ações com relação aos mais habilidosos.

Dando continuidade à história, Ulisses Pernambuco em 1925, criou a primeira escola para crianças excepcionais do país no estado de Pernambuco (ANDRADE, 2009). E no ano de 1930 houve a publicação de "A educação dos Supernormais", de Leoni Kaseff (CUPERTINO, 2012).

No entanto, as primeiras discussões no Brasil sobre atendimento às pessoas com $\mathrm{AH} / \mathrm{SD}$ marcam a década de 1920, conforme registra Osowiski (1989, p. 24):

No Brasil, desde a década de 1920, é possível encontrar estudos, experiências-piloto, artigos e livros tratando desse tema. Inicialmente, eram atividades esporádicas, mas que revelavam a preocupação que perspassava alguns brasileiros. No fim da década de vinte início da década de trinta, pesquisas foram realizadas aqui no Brasil com o objetivo de identificar o número dos chamados superdotados. Foi feita uma estimativa que haveria, na época, em torno de 172.000 pessoas consideradas superdotadas dentre uma população de 40.000.000 de habitantes.

Desde 1924 a educação dos estudantes brasileiros com altas habilidades/superdotação, passa pelo contraste entre a continuidade e a descontinuidade de iniciativas governamentais, que datam as primeiras validações de testes de inteligência americanos em Recife e no Distrito Federal (DELOU, 2001).

Em 1929, houve o primeiro registro de atendimento realizado aos estudantes com altas habilidades/superdotação, no Brasil, quando a Reforma do Ensino Primário, Profissional e Normal do Estado do Rio de Janeiro previu o atendimento educacional dos super-normaes, termo utilizado na época por Leoni Kaseff. Porém, mesmo com esta medida não garantiu o direito declarado na legislação do Estado do Rio de Janeiro, uma vez que não foi seguida de uma política pública estadual ou federal, que universalizasse $o$ atendimento escolar a esses alunos (DELOU, 2007).

Entre as muitas idéias inovadoras que trouxe para o Brasil, Helena Antipoff enfatizou a da educação dos "excepcionais". Fundadora da Sociedade Pestalozzi de Belo Horizonte, em 1938 identificou 8 (oito) crianças super-normaes nomeando-as como crianças bem-dotadas. No ano seguinte, a mesma propôs a inclusão de um parágrafo nos estatutos da instituição (DELOU, 2007).

Foi na Sociedade Pestalozzi do Rio de Janeiro que iniciou os primeiros atendimentos a estudantes identifica- 
dos com AH/SD e foi nesta instituição que se realizaram os dois primeiros seminários sobre Superdotação, em 1966 (OLIVEIRA, 2015).

Somente com o processo de industrialização da sociedade capitalista, a partir da década de 70, começou a surgir o interesse em garantir um atendimento especial para estudantes com altas habilidade/superdotação. A Lei $\mathrm{n}^{\circ} 5.692$, de 11 de agosto de 1971, no seu artigo nono, ressalta a garantia ao atendimento especial para os esses estudantes (BRASIL. 1971).

Em agosto de 1971, foi promulgada a Lei ${ }^{0} 5692$ que previa que tal como os alunos que apresentassem deficiências físicas ou mentais os superdotados também deveriam receber tratamento especial, de acordo com as normas fixadas pelos competentes Conselhos de Educação (BRASIL, 1971, Artigo 9º). Decorrentes disso foram criados o Núcleo de Apoio à Aprendizagem do Superdotado (1975) e a Associação Brasileira de Superdotação (1978) (GAMA, 2006).

Entre as iniciativas destaca-se o Centro para Desenvolvimento do Potencial e Talento (CEDET), criado em 1993, na cidade de Lavras/MG, sob a coordenação de Zenita Guenther, que agia identificando, acompanhando e estimulando os potenciais, procurando preservar a formação integral da criança superdotada. No mesmo ano foi realizado um programa na Universidade Federal Fluminense, coordenado por Cristina Delou, permitindo, entre outras ações, a participação de estudantes com AH/SD em aulas do ensino superior (GAMA, 2006).

A Resolução do Conselho Nacional de Educação/ Câmara de Educação Básica no 02, de setembro de 2001, do Ministério da Educação, faz menção ao termo modificando a estrutura, substituindo "Altas Habilidades ou Superdotação" por "Altas Habilidades/Superdotação" (CORDÃO, 2001). No ano seguinte, em 2002, no Estado do Espírito Santo, estudiosos e pesquisadores na área da Educação Especial reuniram-se no II Seminário de Educação Inclusiva para discutir sobre a necessidade de apoiar os direitos dos alunos superdotados. Após esse encontro, em 2003, foi criado o Conselho Brasileiro para Superdotação, uma instituição não governamental com a finalidade de assegurar os interesses dos alunos superdotados.

Em 2003, criaram -se o Conselho Brasileiro de Superdotação (ConBraSD) envolvendo profissionais e interessados na área. No mesmo ano, iniciou em Santa Maria/ RS, um projeto de extensão universitária, coordenado pela Professora Soraia Napoleão Freitas, docente da Universidade Federal de Santa Maria, que se intitulava Programa de Incentivo ao Talento (PIT) (OLIVEIRA, 2009).

O Ministério da Educação/ Secretaria de Educação Especial, em parceria com os Estados e Distrito Federal 
implantou em 2005, como projeto piloto, Núcleos de Atividades e Altas Habilidades/Superdotação em todo país. A iniciativa teve por objetivo oferecer subsídios às escolas para que identificassem e promovessem o talento entre os estudantes, estimulando a criatividade e promovendo o desenvolvimento pleno do potencial de seus alunos.

É importante ressaltar que durante o ano de 2006 até a presente data (2020) houve pouco avanço quanto às Altas habilidades/Superdotação. Jara (2019, p. 60-61) afirma que:

De 2006 a 2018, algumas mudanças educacionais e políticas ocorreram no Brasil, especialmente no que diz respeito às políticas públicas. Dentre as principais destacam-se a publicação da Política Nacional de Educação Especial na Perspectiva da Educação Inclusiva (2008); o Decreto $\mathrm{n}^{\circ}$ 6.571, de 17 de setembro de 2008, que estabelece orientações aos sistemas de ensino, a fim de proporcionar o Atendimento Educacional Especializado (AEE) em salas de recursos multifuncionais e determinando a adjudicação de matrícula adicional para os alunos que estejam recebendo AEE; o Parecer $n^{0} 13$ e a Resolução ${ }^{\circ}$ 4, do Conselho Nacional de Educação/Câmara de Educação Básica, de 3 de junho e 06 de outubro de 2009, respectivamente, que definem as Diretrizes Operacionais para o AEE na Educação Básica e ampliam as possibilidades de ofertas de AEE para outros espaços educacionais não-formais; e o Plano Nacional de Educação (2011), que estabelece metas estratégicas para ampliação do AEE para a Educação Especial e as AH/SD.

Supõe-se importante também ressaltar que no ano de 2010 foi feita uma pesquisa de participação dos NAAH/S em funcionamento no Brasil, abrangendo somente 18 deles. No ano de 2017 outra pesquisa buscou identificar, em todo o território nacional, onde havia atendimento para alunos com AH/SD. A pesquisa mais recente apontou um total de 45 locais que oferecem Atendimento Especializado ( $\mathrm{AEE}$ ) para $\mathrm{AH} / \mathrm{SD}$, porém apenas 32 informaram a manutenção do vínculo normativo-metodológico com o programa. Doze deles seguem o programa "na íntegra" e 20 o seguem "em parte" (RIBEIRO, 2017). Como um parâmetro geral Ribeiro (2017, p. 35) conclui que:

A realidade situacional dos programas/projetos, da parte da rede pública, especialmente, evidencia que essa estrutura, nos anos que se sucederam ao seu lançamento, foi perdendo gradativamente a força adquirida. Significa que não passou por um processo cuidadoso 
de reestruturação, de monitoramento e avaliação, procedimento imprescindível, visto que, em dez anos, a realidade certamente se transforma [...] por não sustentar o apoio prestado à época do lançamento, na mesma proporção da fidelização que os dados expressam, por parte dos programas/projetos [...] a estagnação pode induzir ao estado em que se encontra o funcionamento desses programas atualmente (RIBEIRO, 2017, p. 35).

Sendo assim, é importante observar que o NAAH/S, como órgão de gestão das políticas para os estudantes com Altas Habilidades/Superdotação ensejou algumas ações públicas na inserção de políticas de atendimento educacional para esse público em algumas regiões do Brasil. Porém, ainda está longe de atingir a maioria dos estudantes com Altas Habilidades/Superdotação em todo território nacional, seja por lacuna ou ineficiência aa legislação ou por ausência de iniciativa federal frente à cobrança e monitoramento nos estados sobre a sustentação dos núcleos.

\section{0 trabalho da rede estadual de ensino em Campo Grande-MS para AH/SD}

Com o objetivo de atender ao que está disposto na Lei de Diretrizes e Bases (LDB) (BRASIL, 1996), o governo do Estado do Mato Grosso do Sul iniciou um processo de identificação com o intuito de encontrar alunos com altas habilidades/superdotação na rede regular de ensino com a implementação do Núcleo de Atividades de Altas Habilidades/Superdotação, em 2005.

O trabalho do NAAH/S -MS é baseado nos 4 volumes de uma série de livros disponibilizados pelo MEC, denominada "A Construção de Práticas Educacionais para o Aluno com Altas Habilidades/Superdotação" (BRASIL, 2007) e da fundamentação teórica proposta por Renzulli (1986). Esse é o acervo que contém subsídios teóricos e práticos para o suporte do trabalho dos técnicos do NAAH/S.

A estrutura desenvolvida pelo NAAH/S - MS é fundamentada no Documento Orientador (BRASIL, 2006), estruturada em três unidades: Unidade de Atendimento ao Aluno, Unidade de Atendimento à Família e Unidade de Atendimento à Escola. Cada unidade tem seus objetivos específicos, mas em todos os momentos se correlacionam, buscando identificar/atender todos os aspectos que envolvem o mundo educacional deste educando. É importante ressaltar que esse documento permite que cada estado faça as adequações necessárias.

O reconhecimento crescente de que as necessidades do superdotado passam pelas áreas cognitiva, afetiva e social, deve ser levado em conta nas propostas de atendimento. 
O decreto $\mathrm{n}^{0}$ 7.611, de 17 de novembro de 2011 inclui as pessoas com com altas habilidades/superdotação no público-alvo da educação especial e garante suplementação da formação desses estudantes pelo atendimento educacional especializado que é o "conjunto de atividades, recursos de acessibilidade e pedagógicos organizados institucional e continuamente" (BRASIL, 2011, p. 1-2).

Em âmbito estadual, verificou-se que a fundamentação legal para o funcionamento do NAAH/S - MS, teve início com o Decreto $\mathrm{n}^{0}$ 12.169, de 23 de outubro de 2006, que vincula o referido Núcleo à Coordenadoria de Educação Especial da Superintendência de Políticas de Educação da SED/MS. Ainda em seu Art. $2^{\circ}$ prevê a organização de sua estrutura com as seguintes unidades:

I - Unidade de atendimento ao Professor; II - Unidade de atendimento ao Aluno; III- Unidade de atendimento à Família.

Art. $3^{\circ}$ A Unidade de atendimento ao Professor objetiva oferecer cursos de formação continuada a professores e profissionais de educação, promover pesquisas e realizar planejamento junto a instituições parceiras para desenvolvimento de ações referentes às altas habilidades/superdotação.

Art. $4^{\circ}$ A Unidade de Atendimento ao Aluno objetiva apoiar alunos com altas habilidades/ superdotação, professores e comunidade, por meio de métodos e materiais necessários ao processo de ensino e aprendizagem.

Art. $5^{\circ}$ A Unidade de Atendimento à Família objetiva orientar e dar apoio psicológico e emocional à família, com intuito de incentivar o desenvolvimento das potencialidades dos alunos com altas habilidades/superdotação (MATO GROSSO DO SUL, 2006).

Fazendo as últimas considerações a respeito das legislações neste momento de escrita, trazemos a resolução da SED/MS, que especifica um pouco mais sobre o funcionamento do NAAH/S - MS, na Resolução/SED de 2 de fevereiro de 2012 e estabelece procedimentos para o funcionamento do núcleo, a saber:

Art. $2^{\circ} \mathrm{O}$ NAAH/S - MS tem como objetivos avaliar, identificar e promover atendimento educacional especializado aos alunos com altas habilidades/superdotação da Rede Estadual de Ensino de Mato Grosso do Sul, na Perspectiva da Educação Inclusiva. Art. $3^{\circ}$ Os atendimentos oferecidos pelo NAAH/S - MS será realizado no Centro Estadual de Educação Especial Inclusiva - CEESPI e nas unidades escolares da Rede Estadual de Ensino. 
Parágrafo Único: $\mathrm{O}$ atendimento aos alunos com altas habilidades/superdotação no interior do Estado funcionará sob orientação do NAAH/S - MS.Art. $4^{\circ}$ Para a consecução de sua proposta o NAAH/S - MS oferecerá suplementação curricular aos alunos em atendimento (MATO GROSSO DO SUL, 2012).

A partir das Resoluções e Decretos, podemos observar que existe um trabalho voltado para ações que possam identificar e atender os alunos com altas habilidades/superdotação e que se busca, cada vez mais, compreender e aprimorar as questões voltadas a este tema. Um assunto relevante que tem sido muito discutido e debatido nacional e internacionalmente por diversos autores como Gama (2006), Alencar e Fleith (2001), Delou (2007), com variadas formas de pensamentos e direcionamentos.

Os alunos com altas habilidades necessitam de serviços educacionais diferenciados, que possam promover seu desenvolvimento acadêmico, artístico, psicomotor e social, o que inclui modificação do currículo e métodos de ensino adaptados às suas necessidades especiais.

Segundo relatório de funcionamento do NAAH/S o atendimento é assim organizado: o trabalho é realizado em etapas, primeiramente os técnicos (pedagogo e psicólogo) vão às escolas, conversam com a direção e coordenação escolar, apresentando a proposta de trabalho e oferecendo uma capacitação a toda equipe escolar (coordenação, direção e professores). Dessa forma capacitam esses profissionais para identificarem estudantes com altas habilidades/ superdotação por meio de instrumentos que sinalizam essas características.

A partir dessa capacitação inicial os profissionais da escola, juntamente com os profissionais do NAAH/S, iniciam o processo de identificação de estudantes com altas habilidades/superdotação. Feita a identificação, a família do estudante é chamada, pela gestão escolar, para uma entrevista estruturada que colhe dados a respeito do mesmo e para a solicitação de autorização para o início da avaliação.

Após a autorização da família é iniciada a avaliação individual de cada estudante, que acontece uma vez por semana, em sua própria escola, durante, no mínimo, dois meses. Caso o resultado da avaliação seja positivo ele é encaminhado para o Atendimento Educacional Especializado (AEE) do seu interesse.

A proposta de enriquecimento está explicada nas Diretrizes do MEC, a partir do embasamento teórico de Renzulli (1986) que desenvolveu o modelo "Triárdico de Superdotação", definindo três grupamentos básicos para que uma pessoa possa ser identificada com altas habilidades/ superdotação: capacidade geral e/ou específica acima da 
média, elevados níveis de comprometimento com a tarefa e elevados níveis de criatividade (fig.1).

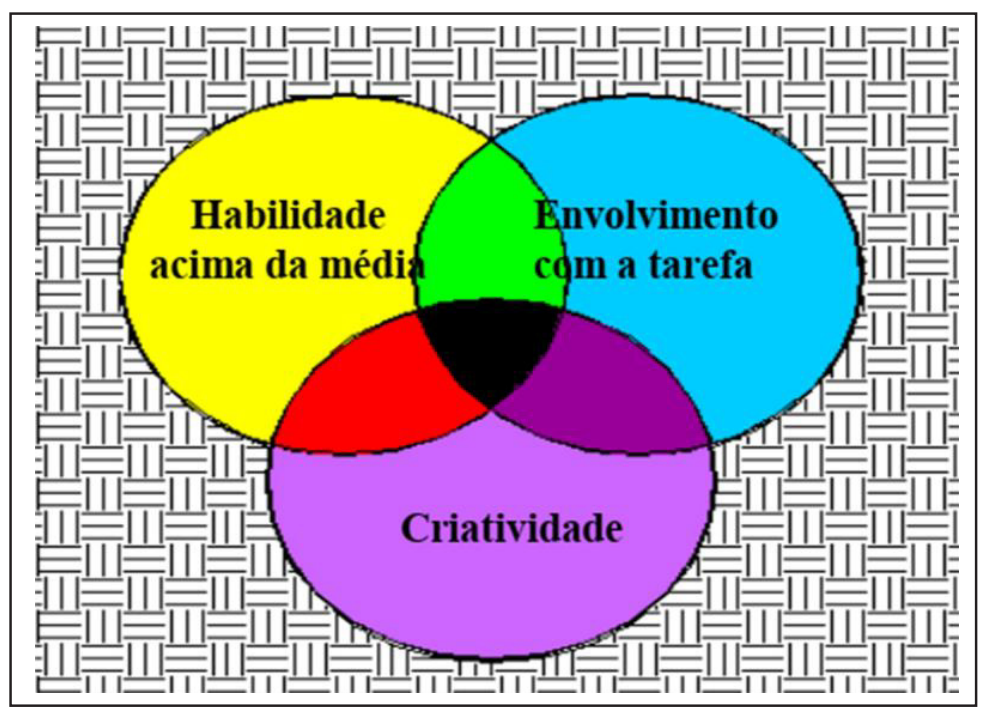

Figura 1 - Modelo dos três anéis de Joseph Renzulli. Fonte: Renzulli (1986, p. 8).

A partir de então, o AEE acontece no espaço físico no NAAH/S, em Campo Grande, MS, no contraturno de horário de aula com o objetivo de oferecer suplementação curricular e outros que se fizessem necessários. Uma das condições para participar do AEE é que a criança ou jovem esteja matriculado na escolar regular e frequentando regularmente. No AEE os alunos desenvolvem as habilidades e encontram pares similares, o que auxilia no seu convívio social.

Esta pesquisa traz como primeiras referências os estudos do programa e da proposta do projeto do MEC, Normas e Legislações (Federais e Estaduais), LDB e referenciais como Renzulli e Reis (1986), Mettrau (2000), entre outros, autores que contribuem com os estudos voltados à altas habilidades/superdotação.

No ano de 2017, por meio do Decreto $\mathrm{n}^{0} 14.786$, de 24 de julho de 2017 foi criado o Centro Estadual de Atendimento Multidisciplinar para Altas Habilidades/Superdotação (CEAM/AHS), que está vinculado pedagógico e administrativamente à Coordenadoria de Políticas para a Educação Especial (COPESP) e a Secretaria de Educação do Estado de Mato Grosso do Sul. (SED/MS) (MATO GROSSO DO SUL, 2017).

O trabalho realizado pelo CEAM/AHS é o mesmo do NAAH/S, porém como Centro pode ter mais autonomia relativa a verbas, propostas e ações, o que facilita o trabalho da equipe. Deve-se ressaltar que o CEAM/AHS tem a sede 
em Campo Grande-MS, sendo o único centro de AH/SD com esse nome no país, porém atende todos os estudantes com altas habilidades/superdotação do estado do Mato Grosso do Sul. Seu público-alvo são estudantes da Rede Estadual de Ensino do MS, uma vez que pertence à SED - MS, porém como centro também pode atender estudantes da rede particular de Ensino. Para que isso ocorra os responsáveis pela escola devem solicitar, à SED, a avaliação do estudante que encaminha o pedido para o Centro. Já os estudantes da rede estadual é atendido na própria escola onde a sua avaliação é feita diretamente pelos técnicos do CEAM/ AHS. Uma vez confirmada as altas habilidades/superdotação são encaminhados para o Atendimento Educacional Especializado (AEE) na sede do centro em Campo Grande. A Rede Municipal de Ensino tem atendimento próprio aos estudantes que requerem atendimento especial.

O CEAMS/AHS adota o conceito de Altas Habilidades/Superdotação disposto na Política de Educação Especial na Perspectiva da Educação Inclusiva (BRASIL, 2008) e o processo de identificação é pautado nos estudos da Teoria das Inteligências Múltiplas de Gardner (1994) e na Teoria dos Três Anéis de Renzulli (1986; 2004).

A avaliação do CEAM/AHS consiste numa análise por meio de atividades que visam reforçar a afinidade do estudante com uma ou mais inteligências (lógico-matemática, linguística, espacial, musical, corporal-cinestésica, naturalista, intrapessoal e interpessoal), e o conceito de Altas Habilidades/Superdotação e concebido como o encontro dos três anéis ( habilidade acima da média, comprometimento com a tarefa e criatividade). Apoia-se nos indicadores de $\mathrm{AH} / \mathrm{SD}$ em qualquer uma dessas inteligências.

Tanto Gardner (1994) como Renzulli (2004) consideram a inteligência em uma concepção multidimensional. Nessa perspectiva, por meio da observação de comportamentos dos estudantes em atividades pedagógicas e criativas, a equipe técnica do CEAM/AHS avalia os estudantes da rede estadual de ensino de Campo Grande. Sendo assim, a avaliação consiste em investigar as potencialidades, por meio de um processo contínuo, flexível e coerente com a sua realidade, considerando os aspectos como o contexto social, motivação intrínseca e o comportamento do estudante. Segundo Gonçalves e Fleith (2016, 285):

[...] vale lembrar que o processo de identificação: faz sentido apenas se acompanhado de um plano educacional ou a um atendimento ou serviço; seja contínuo no sentido de ajudar os alunos a conhecerem e entenderem o seu potencial; seja flexível uma vez que não existe um perfil único de aluno superdotado; seja baseado em uma concepção de 
superdotação validade cientificamente; avalie características dos indivíduos à luz dos contextos escolar, familiar, social, cultural e histórico no qual o aluno está inserido.

De acordo com Galbraith e Delisle (1996 apud, VIRGOLIM, 2007) para um levantamento inicial de características das altas habilidades/superdotação do aluno no contexto escolar, é necessário a atenção do professor à lista de comportamentos elencadas no quadro a seguir (Quadro 1).

Quadro 1- Formulário para identificação das Altas Habilidades/ Superdotação

\begin{tabular}{|c|c|}
\hline 01 & Aprende fícil e rapidamente \\
\hline 02 & Original, imaginativo, criativo, năo-convencional \\
\hline 03 & Amplamente informado; informado $\mathrm{em}$ áreas não comuns \\
\hline 04 & Pensa de forma incomum para resolver problemas \\
\hline 05 & Persistente, independente, auto-direcionado (faz coisa sem que seja mandado) \\
\hline 06 & Persuasivo, capaz de influenciar os outros \\
\hline 07 & Mostra senso comum; pode năo tolerar tolices \\
\hline 08 & Inquisitivo, cético, curioso sobre o como e porque das coisas \\
\hline 09 & Adapta-se a uma variedade de situaçốes e novos ambientes \\
\hline 10 & Esperto ao fazer coisas com materiais comuns \\
\hline 11 & Habilidades nas artes (música, dança, desenho etc.) \\
\hline 12 & Entende a importància da natureza (tempo, lua, sol, estrelas, solo, etc.) \\
\hline 13 & Vocabulário excepcional, verbalmente fluente \\
\hline 14 & Aprende facilmente novas línguas \\
\hline 15 & Trabalhador independente, mostra iniciativa \\
\hline 16 & Bom julgamento, lógico \\
\hline 17 & Flexível, aberto \\
\hline 18 & Versátil, muitos interesses, interesses além da idade cronológica \\
\hline 19 & Mostra insights e percepçōes incomuns \\
\hline 20 & Demonstra alto nível de sensibilidade, empatia com relaçào aos outros \\
\hline 21 & Apresenta excelente senso de humor \\
\hline 22 & Resiste à rotina e repetiçăo \\
\hline 23 & Expressa idéias e reaçōes, freqūentemente de forma argumentativa \\
\hline 24 & Sensivel à verdade e à honra \\
\hline
\end{tabular}

Fonte: Virgolim (2007, p. 44).

Com esse olhar qualitativo e processual, a equipe técnica do CEAM/AHS realiza a identificação, ofertando apoio pedagógico aos estudantes e orientações à família, professores e comunidade de uma maneira geral, enquanto os professores do Atendimento Educacional Especializado (AEE) promovem durante o atendimento o enriquecimento curricular partindo da área de interesse do estudante tendo como objetivo potencializar o desenvolvimento de suas habilidades. 
O AEE tem o objetivo de estimular os potenciais e as habilidades do estudante, além de aprimorar o seu desenvolvimento. Conforme já foi dito, esse atendimento ocorre no contraturno que o aluno está matriculado na escola regular. Assim, considera-se importante o Atendimento Educacional Especializado aos estudantes com altas habilidades/superdotação que poderão dedicar-se aos seus interesses, desenvolver atividades de suplementação escolar, além de entrar em contato com seus pares. Evidencia-se a importância da família e da escola que devem estar empenhadas para melhor atender as necessidades desses estudantes e, consequentemente, melhorar o desenvolvimento pleno de suas habilidades. Cumpre também destacar os programas de enriquecimento que são:

[...] formas possíveis de se disponibilizar a estes alunos um trabalho diferenciado e com recursos e estratégias específicas para atender a suas peculiaridades. Estes programas podem ser complementados com o trabalho do professor em sala de aula, realizando atividades curriculares que considerem estas especificidades (FREITAS; PÉREZ, 2012, p. 13).

O CEAM/AHS baseia as suas ações nas atividades de enriquecimento, que são classificadas em três tipos: o tipo I tem por finalidade apresentar o estudante a diversas áreas do conhecimento com o intuito de perceber seu interesse maior; o tipo II consiste em estimular os estudantes para aplicar os conhecimentos aprendidos e o tipo III compreende a investigação de problemas para a construção de novos conhecimentos (RENZULLI, 2004) (fig.2).

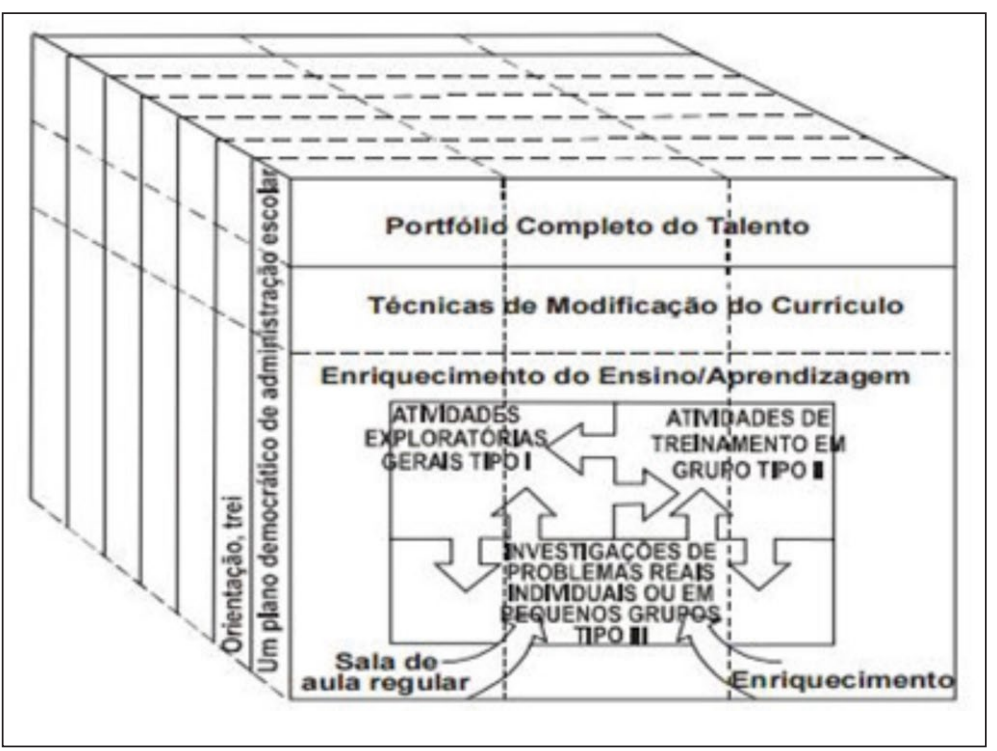

Figura 2 - Modelo de Enriquecimento. Fonte: Renzulli (2004, p. 109). 
Para se obter êxito no desenvolvimento de propostas metodológicas diferenciadas, que sanem as necessidades educacionais especiais, por meio de ambientes estimuladores e desafiadores, precisam-se de

objetivos que propiciem ao estudante um alto potencial a desenvolver ao máximo os seus talentos e habilidades, favorecendo o desenvolvimento global, de tal forma que venha a dar as maiores contribuições possíveis à sociedade, possibilitando-lhe, ao mesmo tempo, viver de uma forma satisfatória, fortalecendo um autoconceito positivo, ampliando as experiências desses alunos em uma diversidade de áreas e não apenas em uma área especializada do conhecimento, desenvolvendo no aluno uma consciência social e possibilitando uma maior produtividade criativa (ALENCAR; FLEITH, 2001, p. 125).

Sendo assim, o CEAM/AHS tenta buscar subsídios na literatura para aprimorar a cada dia o atendimento aos estudantes com altas habilidades/superdotação, considerando ser este um direito deles e possibilitando o desenvolvimento e reconhecimento do potencial de cada estudante, bem como suprindo e suplementando suas necessidades.

\section{Considerações finais}

No espaço escolar, existe uma diversidade de realidades em relação aos alunos, que trazem suas significações de vida, seus valores e sua educação de casa. Na convivência diária com os alunos, é possível identificar inúmeras questões como dificuldades de aprendizagem, de socialização, entre outras, bem como potencialidades em vários aspectos, de alunos que se destacam frente a uma atividade específica ou várias delas.

Assim, como profissionais da educação, compreende-se que é preciso fazer os direcionamentos necessários contribuindo com os estudantes, tanto nas questões de dificuldades, quanto nas suas potencialidades, proporcionando o estímulo necessário e fazendo os devidos encaminhamentos para outros profissionais que possam contribuir em uma ação interdisciplinar.

Com o estudo mediante a pesquisa bibliográfica a respeito da trajetória NAAH/S e CEAM/AHS, foi possível concluir que a temática ainda está em crescimento no cenário educacional. Ainda que se fale muito tempo sobre isso, a prática ainda está aquém, caminhando para o esperado reconhecimento destes indivíduos superdotados e um trabalho adequado com vista na sua inclusão. 
Os alunos com altas habilidades/superdotação são público-alvo da Educação Especial e faz-se necessário a reorganização do ensino, frente às suas especificidades, para que a escolarização seja adequada ao seu desenvolvimento e para que a sua inclusão educacional realmente aconteça.

A criação do Núcleo de Atividade de Altas Habilidades/Superdotação (NAAH/S) e em sequência a consolidação do (CEAM/AHS) como um programa de âmbito federal e parceria com os estados, trouxe melhorias no atendimento ao público da educação especial dentro da rede de escolas estaduais de Mato Grosso do Sul, especialmente em Campo Grande, aumentando o percentual de alunos identificados e atendidos. No entanto, há muito que se avançar na inclusão escolar desses estudantes, de forma a proporcionar a sua permanência na escola, combatendo atitudes excludentes adotadas por uma pedagogia que não considera as diferenças e a diversidade presentes na escola

A retomada da história da $\mathrm{AH} / \mathrm{SD}$ proporciona reflexões e indagações sobre o tema, o que fortalece e pode servir de base para o planejamento das políticas educacionais para esse grupo, de forma a proporcionar aporte aos avanços em relação aos processos de escolarização, principalmente a mim que faço parte desse grupo de profissionais que atuo dia-a-dia com este público.

\section{Referências}

ALENCAR, E. M.L.S.; FLEITH, D. S. Superdotados: determinantes, educação e ajustamento. São Paulo: EPU, 2001.

ANDRADE, M. C. Ulysses Pernambucano. Recife: Pesquisa Escolar Online, Fundação Joaquim Nabuco, 2009. Disponível em: http://goo.gl/hrk5e1> (http://goo. gl/hrk5e1). Acesso em: 09 set. 2018.

BOARINI, M.L; BORGES, R. F. Hiperatividade, higiene mental e psicotrópicos: enigmas da caixa de Pandora. Maringá: EDUEM, 2009.

BRASIL. Decreto n. 7.611, de 17 de novembro de 2011. Dispõe sobre a educação especial, o atendimento educacional especializado e dá outras providências. DF: DOU, 17 nov. de 2011. Disponível em: http://www. planalto.gov.br/ccivil_03/_ato2011-2014/2011/decreto/ d7611.htm. Acesso em: o9 set. 2020.

BRASIL. Ministério da Educação e do Desporto: Secretaria de Educação Especial. Tendências e Desafios da Educação Especial. Brasília: SEESP, 1994. 
BRASIL. Ministério da Educação e do Desporto. Secretaria de Educação Especial. Subsídios para organização e funcionamento de serviços de educação especial: área de altas habilidades. Brasília, DF, 1995. (Série Diretrizes).

BRASIL. Secretaria de Educação Especial. Documento Orientador - Execução da Ação. Brasília: MEC, 2006.

BRASIL. Ministério da Educação. Secretaria de Educação Especial. Política nacional de educação especial na perspectiva da educação inclusiva. Brasília, $D F$ : MEC/SEESP, 2008.

CERVO, Amado Luiz; BERVIAN, Pedro Alcino. Metodologia Científica. São Paulo: Mc Graw-Hill do Brasil, 1976.

DELIBERAÇÃO CEE/MS N. 9367 de 27 de setembro de 2010. Dispõe sobre o Atendimento Educacional Especializado na educação básica, modalidade educação especial, no Sistema Estadual de Ensino de Mato Grosso do Sul.

CUPERTINO, C.M.B. (Org.). Um olhar para as altas habilidades: construindo caminhos. 2. Ed. rev. Atual. E ampl. São Paulo: CENP/CAPE/FDE, 2012.

DELOU, C. M. C. Educação do aluno com altas habilidades/ superdotação: legislação e políticas educacionais para a inclusão. In: FLEITH Denise de Souza (Org) A construção de práticas educacionais para alunos com altas habilidades/superdotação: vol 2: atividades de estimulação de alunos. Brasília: Ministério da Educação, Secretaria de Educação Especial, 2007, p. 49-59.

FACHIN, O. Fundamentos de metodologia. 4. ed. São Paulo: Saraiva, 2003.

FREITAS, S.N; PÉREZ, S.G.P.B. Altas habilidades/ superdotação: atendimento especializado. 2 ed. Marília: ABPEE, 2012.

GAMA, M.C.S.S. Educação de Superdotados: teoria e prática. São Paulo: EPU, 2006.

GARDNER, H. Estruturas da mente: a teoria das inteligências múltiplas. Porto Alegre: Artes Médicas, 1994.

GALBRAITH, J.; DELISLE, J. The gifted kid's survival guide: A teen handbook. Minneapolis, MN: Free Spirit Publishing, 1996. In: VIRGOLIM, A. M. R. Altas 
Habilidades/Superdotação: Encorajando Potenciais. Ministério da Educação. Brasília, DF: MEC, SEESP, 2007.

GONÇALVES, F. C.; FLEITH, D.S. Alternativas de identificação de alunos superdotados. In: PISKE, F. H. R.; MACHADO, J. M. S. B.; STOLTZ, T.; (eds.). Altas habilidades/superdotação (AH/SD) e criatividade: identificação e atendimento. Curitiba: Juruá, 2016, p. 277-288.

JARA, G. C. Núcleos de Atividades de altas habilidades/ Superdotação (NAAH/S): Política Educacional para o estado de mato Grosso do Sul. Dissertação (Mestrado). Educação. Universidade Católica Dom Bosco.119 fls. 2019. Campo Grande: UCDB, 2019.

LAKATOS, Eva Maria; MARCONI, Marina de Andrade. Pesquisa. Técnica de pesquisa 3.ed. rev. e ampl. São Paulo: Atlas, 1996.

MATO GROSSO DO SUL. Cria o Centro Estadual de Atendimento Multidisciplinar para Altas Habilidades/Superdotação (CEAM/AHS), com sede no Município de Campo Grande. Decreto $n^{\mathrm{o}}$ 14.786, 24 jul. 2017. Disponível em: <http:// aacpdappls.net.ms.gov.br/appls/legislacao/secoge/ govato.nsf/fd86oode8a55c7fc04256b210079ce25/ 8488c7001668f7d3042581680043e162?OpenDocument. Acesso em: 09 set. 2020.

MATO GROSSO DO SUL. Decreto no 12.169, de 23 de outubro de 2006. Cria o Núcleo de Atividades de Altas Habilidades/Superdotação - NAAH/S, com sede no Município de Campo Grande. Diário Oficial n. 6.834, Campo Grande, MS, 24 out. 2006. Ano XXVIII, p. 3. Disponível em: https://www.normasbrasil.com.br/norma/decreto12169-2006-ms_137341.html. Acesso em: o9 set. 2020.

MATO GROSSO DO SUL. Secretaria de Estado de Educação. Fortalecimento da Gestão Escolar (2007- 2014). In: MATO GROSSO DO SUL. Mensagem à Assembleia Legislativa de Mato Grosso do Sul 2012: governador André Puccinelli. Campo Grande, 2 fev. 2012. Disponível em: http://www.servicos.ms.gov.br/semade_download/ PPA/PPA\%202015\%20COMPLETO.pdf. Acesso em: 09 set. 2020.

METTRAU, M. B. A representação social da inteligência e os portadores de altas habilidades. In: METTRAU, M. B. (Org). Inteligência: patrimônio social. Rio de Janeiro: Dunya, 2000. 
OLIVEIRA, R. F. C., Alunos dotados e talentosos: estarão eles em minha sala de aula? Dissertação (Mestrado), Programa de pós-graduação em Educação Especial. Universidade Federal de São Carlos. 2015, 141 fls. São Carlos: UFScar, 2015.

OSOWSKI, C. I. Os chamados superdotados: a produção de uma categoria social na sociedade capitalista. Tese (Doutorado) Ciências Humanas e Educação, Universidade Federal do Rio Grande do Sul. 1989, 248 fls. Porto Alegre: UFRGS, 1989.

REBELO, A.S.Osimpactos da política de atendimento educacional especializado: análise dos indicadores educacionais de matrículas de alunos com deficiência. 2012. Dissertação (Mestrado em Educação Social). Universidade Federal de Mato Grosso do Sul, Corumbá, 2012.

RECH, A. FREITAS, S. O papel do professor junto ao aluno com Altas Habilidades. Revista Educação Especial. v.2, n. 25, p. 1-7, 2005.

RENZULLI, J. S. The three-ring conception of giftedness: a developmental model for creative productivity. In: STERNBERG, R. J.; DAVIS, J. E. (Eds.), Conceptions of giftedness. New York: Cambridge University, 1986, p. 53-92.

RENZULLI, J. S. The three-ring conception of giftedness: a developmental model for creative productivity. In: RENZULLI, J. S.; REIS, S. M. (Eds.). The triad reader. Mansfield Center: Creative Learning, 1986.

RENZULLI, J. S. O que é esta coisa chamada superdotação, e como a desenvolvemos? Uma retrospectiva de vinte e cinco anos. Educação, n.1 (52), p. 75-131, jan/abr, 2004.

RIBEIRO, O. L. C. Projeto 914BRZ1o42.7. SECADI, 2017. Disponível em: http://portal.mec.gov.br/encceja2/113-concursos-e-selecoes-628061503/selecoes1004321238/33201-editais-2016. Acesso em 09 set. 2020.

Enviado em: 21-07-2020

Aceito em: 13-10-2020

Publicado em: 30-10-2020 